\title{
Age-hardening by miscibility limit in a multi-purpose dental gold alloy containing platinum
}

\author{
Hyo-Joung Seol, Joo-Hee Park, Ri-Mo Ku, Mi-Gyoung Parkª, Yong Hoon Kwon, Hyung-Il Kim* \\ www.goldbulletin.org
}

\begin{abstract}
This study examined the age-hardening by miscibility limit in a multi-purpose dental gold alloy containing platinum. The hardness increased rapidly in the initial stage of the aging process, reached the maximum value, then decreased continuously with aging time. The significant hardness increase resulted from the heterogeneous precipitation of the Pt-rich $\beta$ phase from the grain boundary of the Au-rich $\alpha_{1}$ matrix due to the miscibility limit of AuPt system. With increasing aging time, the fine Pt-rich $\beta$ precipitates covered almost the whole matrix, and by further aging, the precipitates grew coarse. The microstructural coarsening reduced the interface between the Au-rich $\alpha_{1}$ matrix and the Pt-rich $\beta$ precipitates, which released the lattice strains between the two phases, resulting in a softening effect. In the later stage of aging process, the Au-containing $\mathrm{Pt}_{3}$ In particle-like structure was transformed into the Au-depleted particle-like structure containing relatively large amounts of $\mathrm{Cu}$ resulting from the overlapping miscibility limit of both Au-Pt and Ag-Cu systems, which was responsible for the slow decreasing rate in hardness in the later stage of aging.
\end{abstract}

Department of Dental Materials, School of Dentistry and Medical Research Institute, Pusan National University, Beomeo-Ri, Mulgeum-Eup, Yangsan-Si, Gyeongsangnam-Do, 626-814, South Korea

a Dept. of Dental Lab. Science, College of Health Sciences, Catholic University of Pusan, \#9, Bugok 3-dong,

Geumjeong-gu, Busan, 609-757, South Korea

* Corresponding author: Hyung-II Kim

Tel: 82-51-240-8231, Fax: 82-51-255-7804,

E-mail: hilkim@pusan.ac.kr

Keywords: precipitation, miscibility limit, age-hardening, $X$-ray diffraction, energy dispersive spectrometer

\section{Introduction}

The physiology of the oral cavity and dental structures together produce a complex environment that promotes corrosion; the electrolytic corrosion between dissimilar metal restorations must be considered [1]. The application of a single alloy for all indications reduces the possibility of corrosion in the oral cavity. For this reason, a new, multi-purpose dental casting gold alloy was developed.

Conventional dental casting gold alloys of type III or IV exhibit obvious age-hardening characteristics by an appropriate heat treatment, and most of the gold alloys for ceramic-metal restorations harden during the firing of the ceramic. Several solid transformations are the probable mechanism by which the hardening process takes place. The AuCu I ordered phase with a face-centered tetragonal (fct) structure plays an important role in the hardening of conventional dental casting gold alloy which belong to type III or IV [2-7]. The ordered phases with a facecentered cubic (fcc) structure play an important role in the hardening of the gold alloy for ceramic-metal restorations [8-11].

The composition of the multi-purpose dental casting gold alloy is dissimilar in alloy composition from the dental casting gold alloy or the gold alloy for ceramicmetal restorations; there are few studies on the agehardening mechanism of the multi-purpose dental casting gold alloy. The present study examines the mechanism of hardening and overaging in a multipurpose dental gold alloy containing platinum. Platinum is one of the minor constituents added in dental casting gold alloy because of the high corrosion resistance and its strengthening effect in a solid solution state. In the gold alloy for ceramicmetal restorations, platinum reduces the thermal coefficient of expansion to facilitate bonding when the ceramic coating is applied to match the 
Table 1: Chemical composition of the alloy

\begin{tabular}{|ccccccccc|}
\hline Composition & Au & Ag & Pt & Cu & In & Zn & Sn & Ir \\
\hline wt\% & 72.1 & 10 & 9.2 & 4.8 & 3.1 & 0.5 & 0.2 & 0.1 \\
at\% & 59.20 & 14.99 & 7.63 & 12.22 & 4.37 & 1.24 & 0.27 & 0.08 \\
\hline
\end{tabular}

surrounding natural teeth. Platinum has a miscibility limit with the major constituent, gold, in the solid state [12], which may or may not affect the age-hardening mechanism depending on the alloy composition. The purpose of the present study is to elucidate the age-hardening mechanism of a multi-purpose dental gold alloy containing platinum, by examining the hardening behavior, phase transformation, changes in microstructure, and element distribution during aging.

\section{Experimental details}

The alloy used in the present study was a multipurpose Au-Ag-Pt-Cu-In alloy (Aurium bio 422, Aurium research, U.S.A.). The chemical composition of the alloy is listed in Table 1. The initial shape of the specimen was plate-like with dimensions of 9 $\mathrm{mm} \times 9.5 \mathrm{~mm} \times 1 \mathrm{~mm}$, and was procured in a rolled and annealed state.

Before hardness testing, the specimens were solution-treated at $850^{\circ} \mathrm{C}$ for 10 min under an argon atmosphere, and then rapidly quenched into ice brine to prevent thermal changes on cooling. Specimens were subsequently aged isochronally for 10 and 20 min in the temperature range of $200^{\circ} \mathrm{C}$ to $550^{\circ} \mathrm{C}$, and were isothermally aged at $350^{\circ} \mathrm{C}$ and $400^{\circ} \mathrm{C}$ for various periods of time. All aging was performed in a molten salt bath, followed by quenching in ice brine. Hardness measurements were made using a Vickers micro-hardness tester (MVK-HI, Akashi Co., Japan) with a load of $300 \mathrm{gf}$ and a dwell time of $10 \mathrm{~s}$. Vickers hardness results were recorded as the average values of 5 measurements.

For the X-ray diffraction (XRD) studies, powder specimens that passed through a 300-mesh screen were obtained by filing the plate-like specimens. After vacuum-sealing in a silica tube and solutiontreated at $850^{\circ} \mathrm{C}$ for $10 \mathrm{~min}$, they were isothermally aged at $350^{\circ} \mathrm{C}$ for various period of time in a molten salt bath, and then quenched into ice brine. The X-ray diffraction profiles were recorded by an X-ray diffractometer (D/Max-2400, Rigaku Denki
Co. Ltd., Japan). The X-ray diffractometer was operated at $30 \mathrm{kV}$ and $40 \mathrm{~mA}$, using Ni-filtered $\mathrm{Cu}$ $\mathrm{K} \alpha$ radiation.

For the filed emission scanning electron microscopic (FE-SEM) observations, the plate-like specimens were subjected to the required heat treatment, and then prepared by utilizing standard metallographic techniques. A freshly prepared aqueous solution of $10 \%$ potassium cyanide and $10 \%$ ammonium persulfate was used for the final etching of the specimens. The specimens were examined at $15 \mathrm{kV}$ using a filed emission scanning electron microscope (JSM-6700F, JEOL, Japan).

For the energy dispersive spectrometer (EDS) analysis, the specimens were prepared in the same manner as was used for the FE-SEM observations. EDS analysis was performed using a field emission

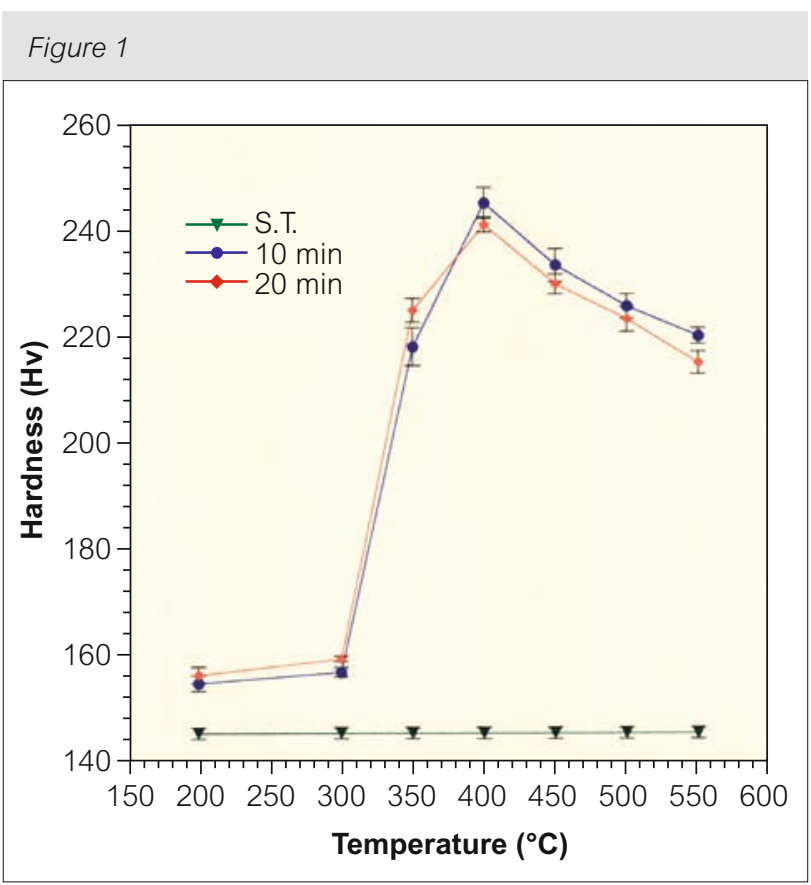

The isochronal age-hardening curves of the specimen alloy solution-treated at $850^{\circ} \mathrm{C}$ for $10 \mathrm{~min}$, and then aged in the temperature range of $200^{\circ} \mathrm{C}$ to $550^{\circ} \mathrm{C}$ for 10 and $20 \mathrm{~min}$ 


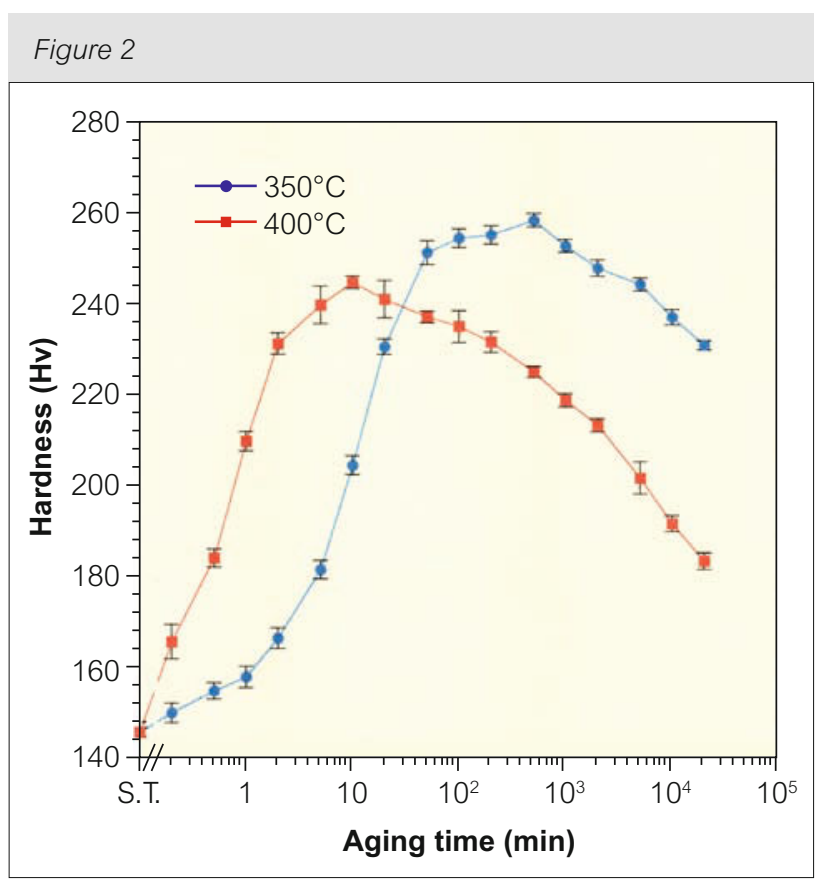

The isothermal age-hardening curves of the alloy solutiontreated at $850^{\circ} \mathrm{C}$ for $10 \mathrm{~min}$ and then aged for various times at $350^{\circ} \mathrm{C}$ and $400^{\circ} \mathrm{C}$

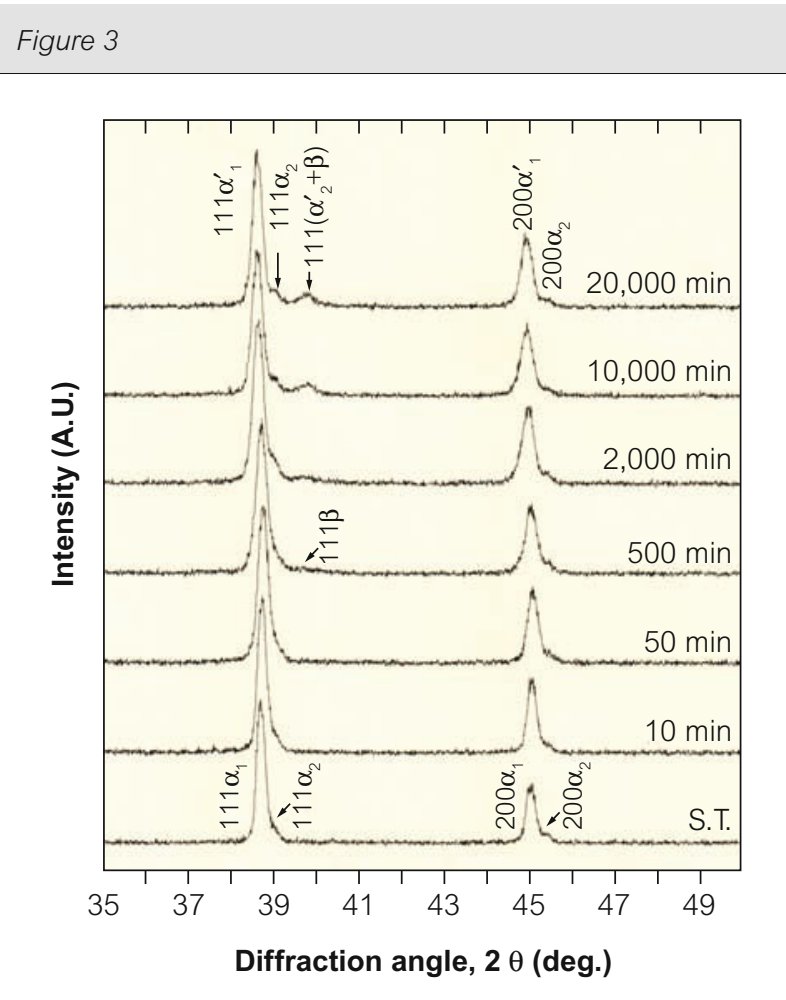

The variations of the $X R D$ pattern during $350^{\circ} \mathrm{C}$ isothermal aging scanning electron microscope (JSM-6700F, JEOL, Japan) equipped with an energy dispersive $\mathrm{X}$-ray spectrometer (INCA x-sight, Oxford Instruments Ltd., UK).

\section{Results and discussion}

\subsection{Hardness change}

To determine an appropriate aging temperature, the specimens were isochronally aged in the temperature range of $200^{\circ} \mathrm{C}$ to $550^{\circ} \mathrm{C}$. Fig. 1 shows the isochronal age-hardening curves of the specimen alloy solution-treated at $850^{\circ} \mathrm{C}$ for $10 \mathrm{~min}$, and then aged in the temperature range of $200^{\circ} \mathrm{C}$ to $550^{\circ} \mathrm{C}$ for 10 and $20 \mathrm{~min}$. The alloy exhibited an apparent age-hardenability near $400^{\circ} \mathrm{C}$. Thus, the age-hardening behavior with aging time was observed at $350^{\circ} \mathrm{C}$ and $400^{\circ} \mathrm{C}$.

Fig. 2 shows the isothermal age-hardening curves of the alloy solution-treated at $850^{\circ} \mathrm{C}$ for $10 \mathrm{~min}$ and then aged for various times at $350^{\circ} \mathrm{C}$ and $400^{\circ} \mathrm{C}$. The isothermal age-hardening curves at $350^{\circ} \mathrm{C}$ and $400^{\circ} \mathrm{C}$ displayed a similar tendency, but the aging rate was more rapid at $400^{\circ} \mathrm{C}$ than at $350^{\circ} \mathrm{C}$ due to the faster atomic diffusion at higher aging temperature [13-16]. The hardness of the solution-treated specimen began to increase and reached a maximum value with increasing aging time, and then the hardness decreased constantly. Considering the overall age-hardening curve, the age-hardenability and the age-hardening behavior were similar at $350^{\circ} \mathrm{C}$ and $400^{\circ} \mathrm{C}$; this suggested that the same age-hardening mechanism occurred at both temperatures.

\subsection{XRD study}

Variations of XRD pattern during isothermal aging were examined to clarify a relation of the phase transformation and the hardness change during aging process. Fig. 3 shows the variations in the XRD pattern during $350^{\circ} \mathrm{C}$ isothermal aging. The XRD pattern of the solution-treated specimen demonstrated two phases, $\alpha_{1}$ and $\alpha_{2}$. The $\alpha_{1}$ phase was the Au-rich phase having a face-centered cubic (fcc) structure with a lattice parameter of $a_{200}=0.4026 \mathrm{~nm}$. The $\alpha_{2}$ phase was an ordered fcc phase based on $\mathrm{Pt}_{3}$ In with a lattice parameter of $a_{200}=0.3992 \mathrm{~nm}$ [17], as it will be shown in section 3.4.

By aging the solution-treated specimen at $350^{\circ} \mathrm{C}$ for 20,000 min, the $\alpha_{1}$ phase was transformed into the $\alpha_{1}{ }^{\prime}$ phase with $a_{200}=0.4028 \mathrm{~nm}$ by precipitating 
the $\beta$ phase. The $\alpha_{2}$ phase was in the process of transformation into the $\alpha_{2}^{\prime}$ phase, showing a peak overlap with the $\beta$ phase at the aging time of 20,000 min, this will be described further later. Upon analysis it was determined that the $\beta$ phase was the Pt-rich fcc phase with the lattice parameter of $a_{111}=0.3926$ $\mathrm{nm}$ at the aging time of $500 \mathrm{~min}$ [18].

Changes in the XRD patterns during the isothermal aging at $350^{\circ} \mathrm{C}$ were examined with respect to the isothermal age hardening curve at $350^{\circ} \mathrm{C}$ (Fig. 2). Until the aging time of 500 min when the maximum hardness value was obtained, the $\beta$ phase of very weak peak intensity formed, and the $\alpha_{1}$ peaks were broadened. The $\alpha_{2}$ peaks did not show apparent changes in position and intensity until reaching the 500 min time point. The broad peaks of the $\alpha_{1}$ phase indicated that the lattice strains that cause the hardness increase formed in the $\alpha_{1}$ matrix by precipitating the $\beta$ phase $[13,19,20]$.

During the period of hardness decrease after 500 min, the peak intensity of the $\alpha_{2}$ phase decreased, and that of the $\beta$ phase increased. In addition, $\alpha_{1}$ peaks shifted a little toward the lower diffraction angle. Considering the XRD peak position, it can be supposed that the $\mathrm{Pt}_{3} \ln \alpha_{2}$ phase was in the process of transformation into the Pt-rich $\beta$ phase by precipitating In or into the $\mathrm{Pt}_{3} \operatorname{In} \alpha_{2}{ }^{\prime}$ phase with a smaller lattice parameter than the $\alpha_{2}$ phase by absorbing elements of relatively small atomic size from the matrix. This will be clarified in section 3.4. The broad peaks of the $\alpha$ phase remained broad during the transformation of the $\alpha_{2}$ phase, indicating large amounts of lattice strains in the matrix. This corresponded to the fact that the hardness kept a relatively high value for a long time in the later stage of aging process.

\subsection{Microstructural changes}

FE-SEM observations were performed to clarify the microstructural changes related to the hardness changes. Fig. 4 demonstrates the FESEM photographs of 15,000 magnification for the specimens that were solution-treated at $850^{\circ} \mathrm{C}$ for $10 \mathrm{~min}(\mathrm{~A})$ and aged at $350^{\circ} \mathrm{C}$ for $50 \mathrm{~min}(\mathrm{~B}), 500$ min (C), 2000 min (D), 10,000 min (E) and 20,000 min $(F)$. In the solution-treated specimen (A), matrix and particle-like structure were observed. From the XRD peaks intensity, it was clear that the matrix was the $\alpha_{1}$ phase of higher peaks intensity, and the particle-like structure was the $\alpha_{2}$ phase. By aging the specimen at $350^{\circ} \mathrm{C}$ for $50 \mathrm{~min}$ (B) when the hardness increased up to $96 \%$ of the maximum value, the fine precipitates grew and covered more than half of the matrix from the grain boundaries toward the grain interior. By further aging for 500 min (C) when the maximum hardness value was obtained, the fine precipitates covered almost the whole matrix. The particle-like structure of various sizes did not show

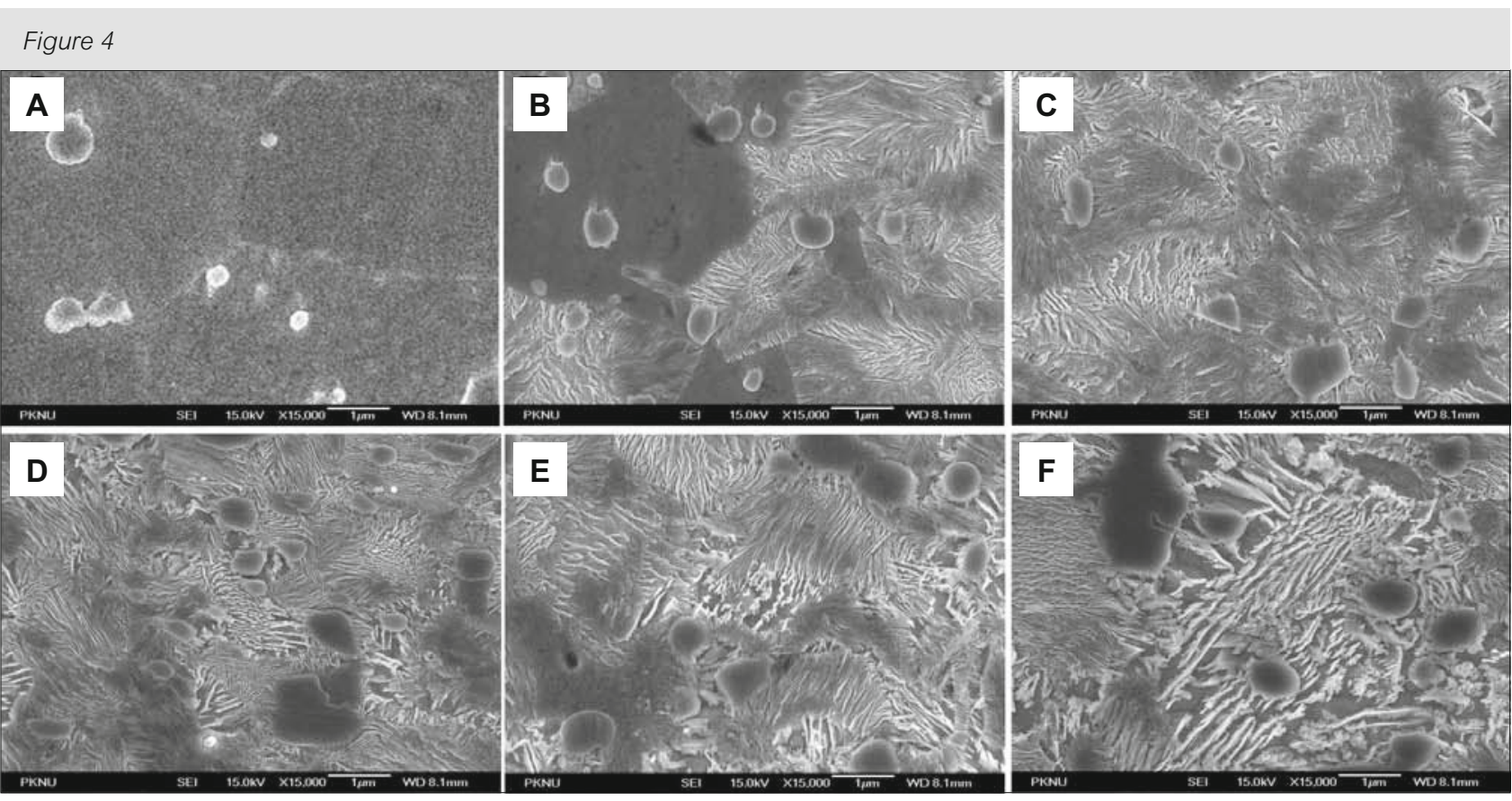

The FE-SEM photographs of 15,000 magnification for the specimens solution-treated at $850^{\circ} \mathrm{C}$ for $10 \mathrm{~min}(\mathrm{~A})$ and aged at $350^{\circ} \mathrm{C}$ for $50 \mathrm{~min}(B), 500 \mathrm{~min}(C), 2000 \mathrm{~min}(D)$, 10,000 $\mathrm{min}(E)$ and 20,000 $\mathrm{min}$ (F) 
apparent changes. Considering the corresponding XRD pattern which showed that the $\alpha_{1}$ peak was broadened as the weak $\beta$ peak appeared, it was judged possible that the significant hardness increase resulted from the heterogeneous precipitation of the Pt-rich $\beta$ phase from the grain boundary of the Au-rich $\alpha_{1}$ matrix due to the miscibility limit of the AuPt system in solid state.

By further aging the specimen for $2000 \mathrm{~min}(\mathrm{D})$, 10,000 min (E), 20,000 min (F) when the hardness decreased by $4 \%, 8 \%$ and $11 \%$ of the maximum value, respectively, the fine precipitates grew coarse with aging time. The microstructural coarsening reduced the interface between the Au-rich $\alpha_{1}$ matrix and the Pt-rich $\beta$ precipitates, which released the lattice strains between the two phases, resulting in a softening effect $[7,11]$. Even with a significant decrease in the $\alpha_{2}$ peak intensity during the period of hardness decrease, the $\alpha_{2}$ particle-like structure did not show apparent microstructural changes. Thus, it was supposed that the $\alpha_{2}$ particle-like structure has undergone severe elemental distributional changes without microstructural changes. To clarify this issue, the EDS analysis was done.

\subsection{The changes of element distribution}

Fig. 5 shows the FE-SEM photographs for the specimens solution-treated at $850^{\circ} \mathrm{C}$ for $10 \mathrm{~min}(\mathrm{~A})$ and aged at $350^{\circ} \mathrm{C}$ for $20,000 \mathrm{~min}(\mathrm{~B})$. The element distribution in the matrix $(\mathrm{M})$, particle-like structure $(\mathrm{P})$ and precipitate (Prec) marked by an arrow were analyzed; the results are displayed in Table 2. In the matrix (M) of Fig. 5-A, an increase in Au, Ag and a decrease in Pt, In was observed compared to the base composition of Table 1. In the particle-like structure (P-1) of Fig. 5-A, large amounts of Pt and In were observed compared to the base composition. The Pt content in the particle-like structure was more than twice that of the In content and the Au content was about 20 at $\%$ in the solution-treated state. This explained that the matrix was composed of the Au-rich $\alpha_{1}$ phase containing $\mathrm{Ag}$ and $\mathrm{Cu}$, and the particle-like structure was composed of the $\mathrm{Pt}_{3} \mathrm{In}$ phase containing Au.
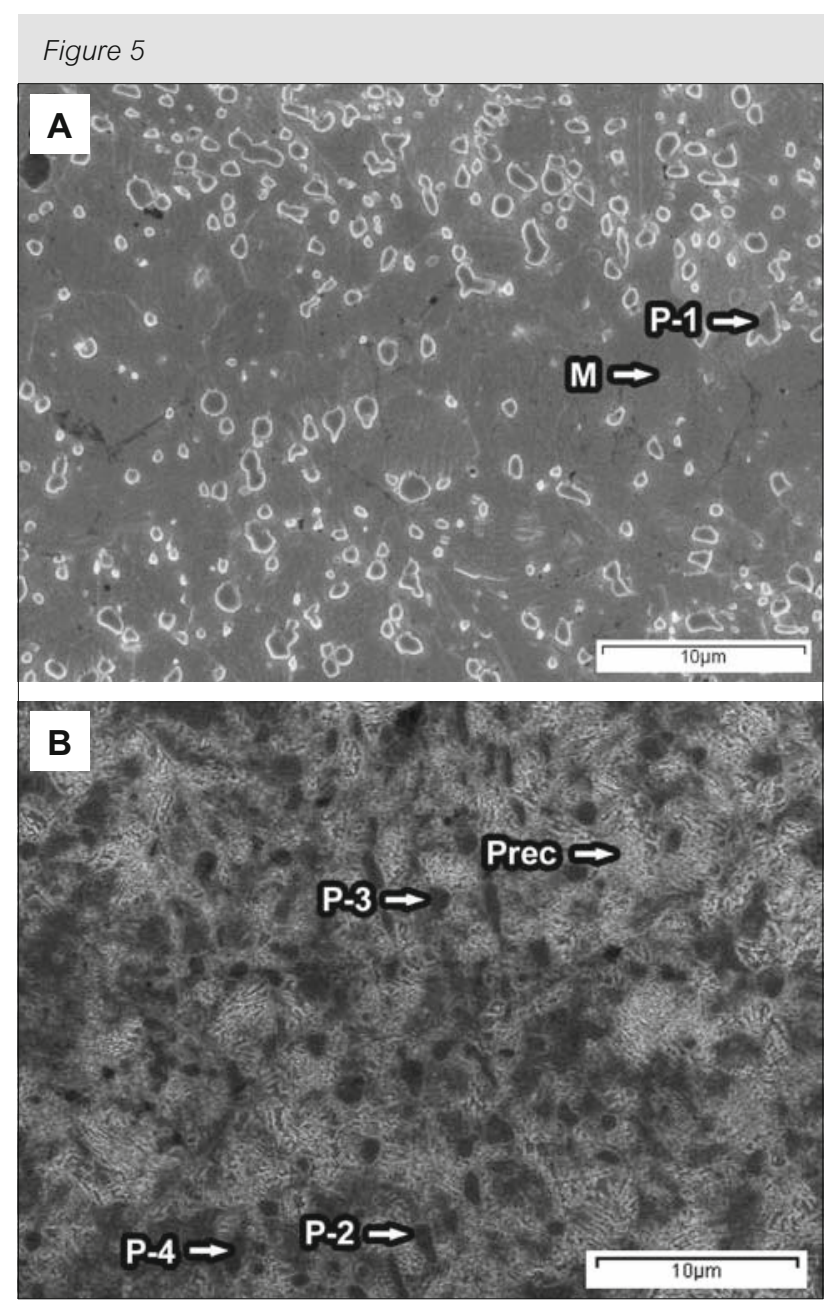

FE-SEM photographs for the specimens solution-treated at $850^{\circ} \mathrm{C}$ for $10 \mathrm{~min}(A)$ and aged at $350^{\circ} \mathrm{C}$ for $20,000 \mathrm{~min}(B)$

Table 2: EDS analysis at the regions marked in Fig. 5

\begin{tabular}{|cccccccc|}
\hline $\begin{array}{c}\text { Region } \\
\text { (at\%) }\end{array}$ & $\mathbf{A u}$ & $\mathbf{A g}$ & $\mathbf{P t}$ & $\mathbf{C u}$ & $\mathbf{I n}$ & $\mathbf{Z n}$ & $\mathbf{S n}$ \\
\hline M & 62.88 & 16.26 & 3.25 & 12.41 & 2.84 & 2.04 & 0.32 \\
P-1 & 20.23 & 0 & 54.67 & 0 & 25.1 & 0 & 0 \\
P-2 & 19.03 & 2.45 & 48.77 & 5.73 & 18.17 & 2.13 & 3.74 \\
P-3 & 7.65 & 2.16 & 45.79 & 18.62 & 18.3 & 4.6 & 2.89 \\
P-4 & 8.54 & 0.72 & 43.18 & 22.88 & 17.92 & 4.18 & 2.59 \\
Prec & 57.23 & 12.24 & 7.62 & 14.91 & 4.26 & 1.52 & 2.22 \\
& & & & & & & \\
\hline
\end{tabular}


In the particle-like structure of the overaged specimen (Fig. 5-B), the P-2 region showed a similar elemental distribution with the $\mathrm{P}-1$ region of the solution-treated specimen (Fig. 5-A). On the other hand, the P-3 and $\mathrm{P}-4$ regions demonstrated an apparent increase in $\mathrm{Cu}$ and a decrease in $\mathrm{Au}$, even though the Pt and In contents had not apparently diverged from those in the P-2 region. $\mathrm{Zn}$ and $\mathrm{Sn}$ which have low melting temperature were also included in the Pt-rich regions of $\mathrm{P}(2-4)$. Considering the changes in the element distribution, the severe XRD pattern changes of the $\alpha_{2}$ phase in Fig. 3 were mainly caused by the atomic diffusion of $\mathrm{Cu}$ and $\mathrm{Au}$. Au and Pt have a miscibility limit for each other in the solid state [21]. In the solution-treated specimen at $850^{\circ} \mathrm{C}$, the $\mathrm{Pt}_{3} \mathrm{In}$ particle-like structure contained Au by 20 at\%, but by aging the specimen at lower temperatures, such as $350^{\circ} \mathrm{C}$, excess amounts of $\mathrm{Au}$ diffused from the Pt-concentrated particle-like structure to the surrounding Au-rich matrix. In the same manner, $\mathrm{Cu}$ which has the miscibility limit for $\mathrm{Ag}$ in solid state, could not dissolve in the Ag-concentrated Au-rich matrix, and thus excess amounts of $\mathrm{Cu}$ diffused to the particle-like structure from the matrix [12]. Based on the evidence described above, it became clear that the Au-containing $\mathrm{Pt}_{3} \mathrm{In}$ particle-like structure was in the process of transformation into the Audepleted particle-like structure containing relatively large amounts of Cu due to the overlapped miscibility limit of both Au-Pt and Ag-Cu systems in solid state. Due to such elemental distributional changes in the matrix and particle-like structure, the hardness decreasing rate became relatively slow even with the progress of coarsening of the Pt-rich $\beta$ precipitates. In the precipitates (Prec) of the overaged specimen (Fig. 5-B), high contents of Au and Ag were detected, and the content of $\mathrm{Pt}, \mathrm{Cu}, \mathrm{In}$ and $\mathrm{Sn}$ increased compared to that in the matrix (M). Considering that the contents of Au and Ag were inevitably reflected from the surrounding Au-rich matrix containing Ag due to the sampling spot size, the precipitates appeared to be the Pt-rich $\beta$ phase containing In, Cu and $\mathrm{Sn}$ at the aging time of 20,000 $\mathrm{min}$.

\section{Conclusions}

Age-hardening by miscibility limit in a multi-purpose dental gold alloy containing platinum was examined, and the following results were obtained.

1 The hardness increased rapidly in the initial stage of the aging process, reaching the maximum value, and decreased continuously with aging time.
2 The hardness increase was caused by the precipitation of the Pt-rich $\beta$ phase from the grain boundary of the Au-rich $\alpha_{1}$ matrix due to the miscibility limit of Au-Pt system in solid state.

3 The microstructural coarsening reduced the interface between the Au-rich $\alpha_{1}$ matrix and the Pt-rich $\beta$ precipitates, which released the lattice strains between the two phases, resulting in a softening effect.

4 The Au-containing $\mathrm{Pt}_{3}$ In particle-like structure was transformed into the Au-depleted particle-like structure containing relatively large amounts of Cu due to the overlapped miscibility limit of both Au-Pt and Ag-Cu systems, which was responsible for the slow decreasing rate in hardness in the later stage of aging.

\section{About the authors}

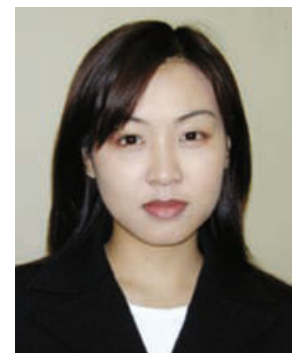

Hyo-Joung Seol is assistant professor of Department of Dental Materials at Pusan National University in South Korea, Ph.D. in 2003. Her research focuses on characterization of the agehardening mechanism of dental alloys.

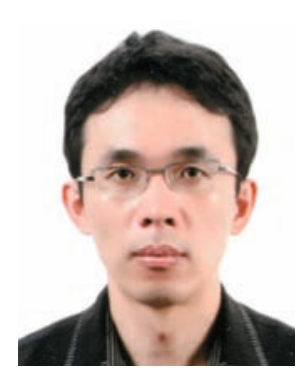

Joo-Hee Park M.Sc. is currently working on research of dental gold alloys in the doctoral course at Pusan National University in South Korea.

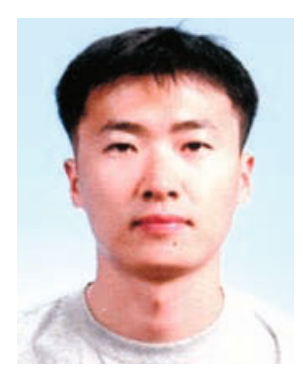

Ri-Mo Ku is currently working on research of dental gold alloys in the master course at Pusan National University in South Korea. 


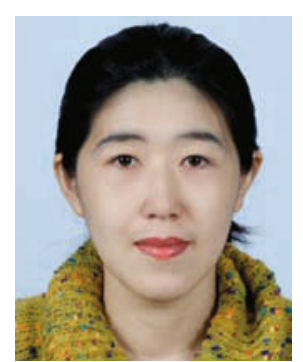

Mi-Gyoung Park Ph.D. is currently working on research of dental gold and alternative alloys at Catholic University of Pusan in South Korea.

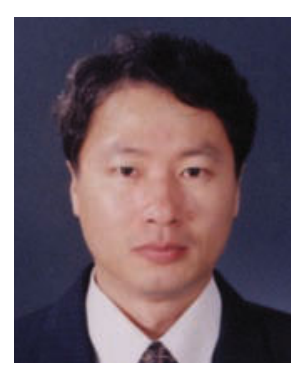

Yong Hoon Kwon is associate professor of Department of Dental Materials at Pusan National University in South Korea, Ph.D. in 1997.

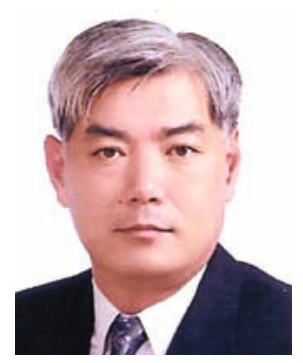

Hyung-Il Kim is chairman of Department of Dental Materials at Pusan National University in South Korea, Ph.D. in 1989. On the editorial board of Dental Materials Journal (International Journal published by the Japanese Society for Dental Materials and Devices).

\section{References}

1 R.W. Phillips, 'Skinner's science of dental materials', 8th ed., W B Saunders Co, Philadelphia, 1982, pp. 290-301.

2 K. Yasuda, M. Ohta, 'Age-hardening characteristics of a commercial dental gold alloy', J. Less-Common Met., 1980, 70, 75

3 K. Yasuda, K. Udoh, K. Hisatsune, M. Ohta, 'Structural changes induced by ageing in commercial dental gold alloys containing palladium', Dent. Mater. J., 1983, 2, 48

4 K. Hisatsune, M. Nakagawa, K. Udoh, B.I. Sosrosoedirdjo, M. Hasaka, 'Age-hardening reactions and microstructures of a dental gold alloy with palladium and platinum', J. Mater. Sci.: Mater. Med., 1990, 1, 49

5 T. Tani, K. Udoh, K. Yasuda, G. Van Tendeloo, J. Van Landuyt, 'Age-hardening mechanisms in a commercial dental gold alloy containig platinum and palladium', J. Dent. Res., 1991, 70, 1350
6 H.I. Kim, M.I. Jang, B.J. Jeon, 'Age-hardening associated with precipitation reaction and spinodal decomposition in a commercial dental low-carat Au-Ag-Cu-Pd alloy', J. Mater. Sci.: Mater. Med., 1997, 8, 333

7 H.I. Kim, M.I. Jang, M.S. Kim, 'Age-hardening associated with grain boundary precipitation in a commercial dental gold alloy', J. Oral Rehabil., 1999, 26, 215

8 D.L. Smith, A.P. Burnett, M.S. Brooks, D.H. Anthony, 'Ironplatinum hardening in casting golds for use with porcelain', J. Dent. Res., 1970, 49, 283

9 R.A. Fuys, C.W. Fairhurst, W.J. O'Brien, 'Precipitation hardening in gold-platinum alloys containing small quantities of iron', J. Biomed. Mater. Res., 1973, 7, 471

10 K. Hisatsune, K. Udoh, M. Nakagawa, K. Yasuda, 'Three distinguishable phase changes during slow-cooling in commercial dental alloys for porcelain bonding', Dent. Mater. J., 1987, 6, 54

11 K. Hisatsune, Y. Tanaka, K. Udoh, K. Yasuda, 'Ageing reactions in a high carat gold alloy for dental porcelain bonding', J. Mater. Sci.: Mater. Med., 1997, 8, 277

12 T.B. Masslski, 'Binary alloy phase diagrams', second ed., ASM international, Materials Park, OH, 1990, pp. 28-29, 414-416

13 Y. Tanaka, K. Udoh, K. Hisatsune, K. Yasuda, 'Early stage of ordering in stoichiometric AuCu alloy', Mater. Trans., JIM., 1998, 39, 87

14 H.J. Seol, D.J. Noh, S.H. Lee, Y.H. Kwon, H.I. Kim, 'Agehardening by the formation of metastable phases in an Inadded Au-Ag-Cu-Pd alloy', Mater Charact, 2008, 59, 1190

15 H.K. Lee, H.M. Moon, H.J. Seol, J.E. Lee, H.I. Kim, 'Age hardening by dendrite growth in a low-gold dental casting alloy', Biomaterials, 2004, 25, 3869

16 Y.C. Suh, Z.H. Lee, M. Ohta, 'Precipitation behavior of AgPd-In dental alloys', J. Mater. Sci.: Mater. Med., 2000, 11, 43

17 P. Villars, L.D. Calvert, 'Pearson's handbook of crystallographic data for intermetallic phases', American Society for Metals, Metals Park, 1985, p. 2562

18 B.D. Cullity, 'Elements of X-Ray Diffraction', second ed., Addison-Wesley publishing Co Inc, Massachusetts, 1978, pp. 506-507

19 G.H. Jeon, Y.H. Kwon, H.J. Seol, H.I. Kim, Gold bulletin, 2008, 3, 257

20 I. Kawashima, H. Ohno, N.K. Sarkar, Dent. Mater., 2000, 16, 75 